\title{
(2) OPEN ACCESS \\ Primary palliative care integrated model in paediatric ICU: an international cross-sectional study
}

\author{
Michelle Grunauer (ㄷ), Caley Mikesell 주 , \\ Gabriela Bustamante Callejas (1), The PICU-MIC Research Group
}

Colegio de Ciencias de la Salud, Universidad San Francisco de Quito, Quito, Pichincha, Ecuador

\section{Correspondence to}

Dr Michelle Grunauer, Colegio de Ciencias de la Salud, Universidad

San Francisco de Quito, Quito 170157, Pichincha, Ecuador; mgrunauer@usfq.edu.ec

Received 5 September 2020 Accepted 25 August 2021
Check for updates

(C) Author(s) (or their employer(s)) 2021. Re-use permitted under CC BY-NC. No commercial re-use. See rights and permissions. Published by BMJ.

\begin{tabular}{|l|}
\hline To cite: Grunauer M, \\
Mikesell C, Bustamante \\
Callejas G, et al. BMJ \\
Supportive \& Palliative \\
Care Epub ahead of \\
print: [please include Day \\
Month Year]. doi:10.1136/ \\
bmjspcare-2020-002627
\end{tabular}

\section{ABSTRACT}

Objectives Numbers are rising of chronically and critically ill, technology-dependent children, who are admitted to paediatric intensive care units (PICUs). An integrated model of care (IMOC), that combines paediatric critical care and primary paediatric palliative care (PPC), in which either approach varies depending on the disease trajectory and is provided by the critical care team, might be a fundamental component of the best available standard of care for patients with life-threatening conditions. The objective of this study is to assess how PICUs around the world, implement an IMOC.

Methods International multicentre crosssectional observational study. Data was gathered from 34 PICUs from 18 countries in the Americas, Europe, Asia and Africa. Provision of primary PPC was studied for each child admitted at the PICU. We evaluated score differences in each domain of the Initiative for Paediatric Palliative Care (IPPC) curriculum with multilevel generalised linear models.

Results High-income country (HIC) units made up $32.4 \%$ of the sample, upper-middle income countries (UMICs) 44.1\%, lower-middle income/ lower income countries (LMIC/LICS) 23.5\%. HICs had four statistically significantly higher IPPC scores compared with UMICs (domains: 1 holistic care; 2 family support, 3B family involvement; 6B grief/bereavement healthcare provider support) and two compared with LMIC/LICS (domains: 6A grief/bereavement family support; 6B grief/ bereavement healthcare provider support). HICs had a statistically significant overall higher IPPC score than UMICs. Adjusting for patient/ centre characteristics, shorter shifts and multiple comorbidities were associated with higher IPPC scores.

Conclusions All centres offered some PPC provision and partially applied an IMOC. These results are encouraging, however, differences related to income and patients/unit evidence opportunities for improvement.

Trial registration number ISRCTN12556149.

\section{Key messages}

What was already known?

- Paediatric palliative care (PPC) access is unevenly available,

- but all children with a life-threatening disease require it.

What are the new findings?

- Centres offered some PPC provision and partially applied an integrated model of care (IMOC).

- High-income countries had a significant overall higher Initiative for Paediatric Palliative Care score than upper-middle income countries.

What is their significance?

(a) Clinical: include these skills during residency training, maximising dissemination of the IMOC.

- (b) Research: translating evidence-based recommendations to practice.

\section{INTRODUCTION}

Palliative care (PC) is a human right ${ }^{1-3}$ and a fundamental component of the best available standard of care for severely ill patients $^{1-6}$ and those with life-limiting or life-threatening conditions. ${ }^{7}$ This multidisciplinary care treats and prevents suffering and is associated with improved quality of care and quality of life for patients and families. ${ }^{1-3}$ 7-9 However, despite the widespread need for PC, approximately $90 \%$ of the 6.3 million children dying each year are unable to access paediatric palliative care (PPC), with 98\% of them living in settings where it is inaccessible. ${ }^{12}$ PPC is inadequately available in worldwide paediatric and neonatal intensive care units (ICUs). ${ }^{1}{ }^{2}$ This reality does not conform with the WHO 's position that all children with a diagnosed lifethreatening disease should have access 
to PPC regardless of whether treatment directed at the disease is provided or not. ${ }^{2}$ In ICUs where it does exist, PC is most commonly made available through external consultation models. ${ }^{15}$ In the less common integrated model of care, ICU providers identify and address primary PPC needs as they arise. ${ }^{1}$ Studies directly comparing these models are limited, but the integrated model of care (IMOC) may better facilitate primary PPC delivery, build local PPC capacity, and make primary PPC available in under-resourced environments. ${ }^{1}$

Building primary PPC capacity and providing an integrated model of care in paediatric ICUs (PICUs) depends on a chain of interventions, ${ }^{2}$ including the development of evidence-based recommendations. An example is the Initiative for Paediatric Palliative Care (IPPC) curriculum, which was developed by the Institute of Patient and Family Centered Care for children with life-threatening conditions and their families (box 1). ${ }^{10}$ It includes different quality domains, goals and indicators that are based on the best standard of care. The curriculum outlines six domains of quality palliative care for paediatric patients: holistic care of the child, support of family unit, involvement of the family and child in decision-making, communication and planning of care, treatment of pain and other symptoms, continuity of care and support of grief and bereavement. ${ }^{10}$ The implementation effectiveness of such interventions is dependent on factors related to the curriculum itself, the implementation environment, potential adopters and implementation resources. ${ }^{11-13}$

As previously mentioned, the successful implementation of the IPPC curriculum requires an intimate understanding of potential adopters and their clinical environments. ${ }^{13}$ For example, practitioners' existing knowledge and skills ${ }^{12-14}$ play a vital role in new clinical learning. ${ }^{14}$ Similarly, unit characteristics like infrastructure, ${ }^{15}$ staff-patient ratio, ${ }^{15-17}$ innovation adoption, ${ }^{13}$ clinical environments ${ }^{13}$ and technology ${ }^{17}$ shape care provision and outcomes. ${ }^{15}$ As such, identifying existing primary PPC resources and competencies among potential IPPC adopters can help improve the uptake of such interventions in new clinical environments.

The objective of this study was to assess if PICUs around the world apply the domains, goals and indicators for each admitted child described in the IPPC curriculum, contributing to an IMOC. A secondary objective was to identify whether unit physical environment, technological infrastructure, human resources and income categories (as defined by the World Bank) ${ }^{18}$ or patient characteristics (sex, race, first language, age, presence of comorbidities) are associated with differences in primary PPC provision. We hypothesised that all centres would at least partially comply with the IPPC curriculum, irrespective of country income and provide an IMOC to a certain extent.
Box 1 Quality domains, goals and indicators for family-centred care of children living with lifethreatening conditions-the Initiative for Paediatric Palliative Care ${ }^{10}$

The Initiative for Paediatric Palliative Care (IPPC): Quality domains, goals and indicators for family-centred care of children living with life-threatening conditions (adapted from the IPPC). ${ }^{10}$

1.0 Domain Holistic Care of the Child

Goal: The needs of each child with a life-threatening/ life-limiting condition are supported and his/her potential promoted in the following six areas: physical, social, emotional, developmental, spiritual and educational.

2.0 Domain 2 Support of the Family Unit

Goal: Each family of a child with a life-threatening/ life-limiting condition receives the support and resources it needs to maintain its integrity.

3.0 Domain 3: Involvement of Child and Family in Communication, Decision-Making and Care Planning

Goal A: Each child with a life-threatening condition is informed about and involved in decisions about his/her own care and care planning to the extent possible based on developmental abilities and desires.

Goal B: The healthcare institution and providers support the opportunity for each family of a child with a lifethreatening condition to be involved in decision-making and care planning with and for its child, respecting the level of involvement desired.

4.0 Domain 4: Relief of Pain and Other Symptoms Goal: Each child with a life-threatening/life-limiting condition receives effective pain and symptom management. 5.0 Domain: Continuity of Care

Goal A: Each child with a life-threatening/life-limiting condition has a written plan of care, which is documented and communicated across all care settings.

Goal B: Each child with a life-threatening condition has a designated individual, a physician or other healthcare provider, who is identified as responsible for coordinating the child's overall care.

6.0 Domain: Grief and Bereavement Support

Goal A: Each family of a child with a life-threatening/lifelimiting condition is offered grief and bereavement support before and after the child's death.

Goal B: Healthcare providers working with children with life-threatening/life-limiting conditions and their families are offered grief and bereavement support.

\section{METHODS}

This international multicentre cross-sectional observational study was completed in 34 PICUs in a mixture of urban, suburban and rural areas of 18 countries in the Americas, Europe, Asia and Africa between 2016 and 2018. Four of the ICUs included self-identify as paediatric and neonatal ICUs. Participants were medical doctors and nurses from PICUs; healthcare providers not employed in PICUs were excluded. Participating centres were identified through medical societies, research networks including the Pediatric Acute Lung 
- High income $\quad \square$ Upper middle income $\quad \square$ Low and lower middle income

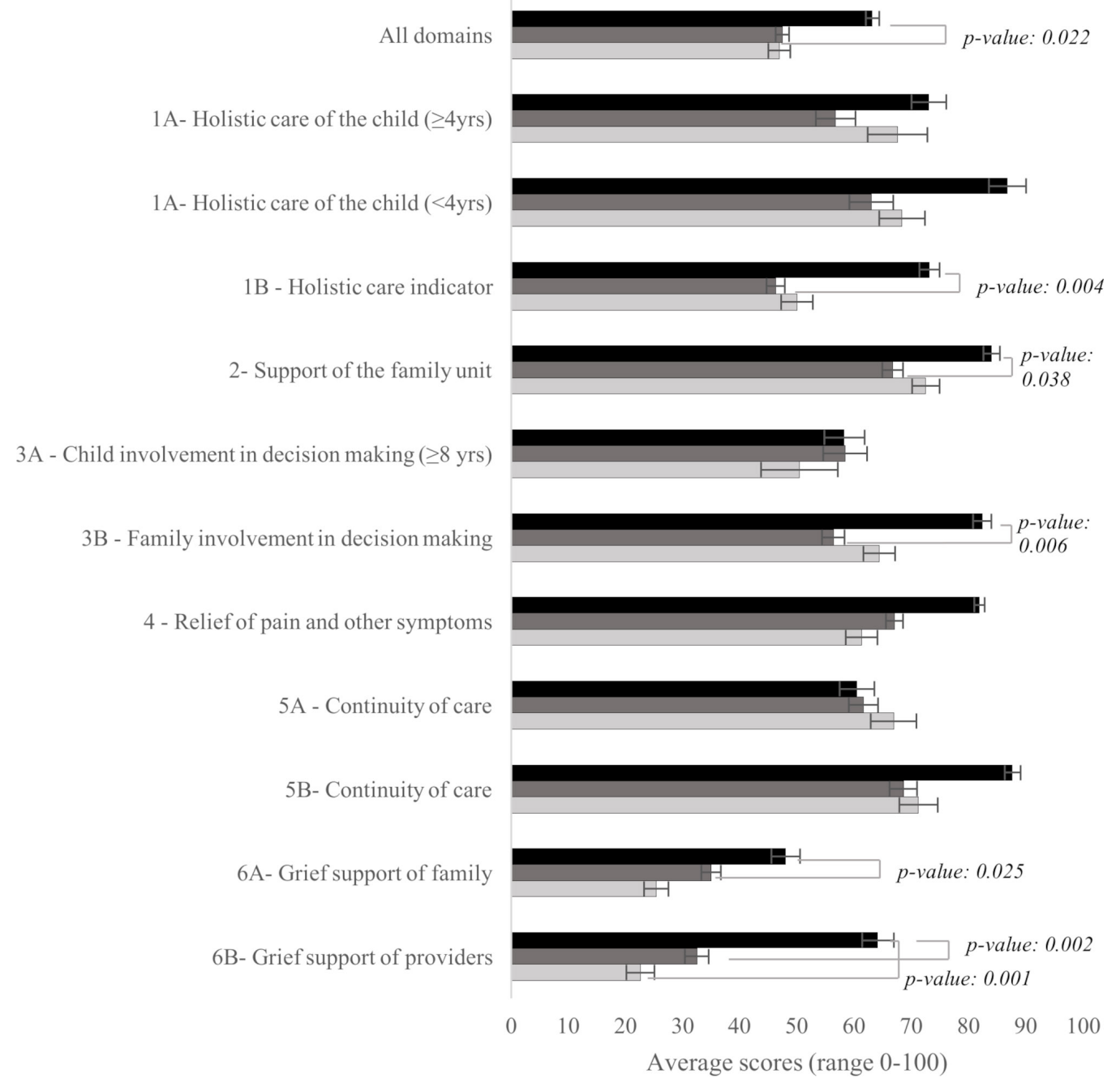

Figure 1 Average Initiative for Paediatric Palliative Care domain scores by World Bank Income Level. * Items referring to educational needs were only considered for children $\geq 4$ years (Domain 1 -holistic needs) to account when formal schooling generally starts around the world. † Items regarding decision-making ability were only considered for children $\geq 8$ years because guidelines recommend involving them in healthcare decisions. ₹ P values were estimated using generalised linear models adjusted for child's age and sex and using centre as a clustering variable.

Injury and Sepsis Investigators Network, publication database searches and team contacts.

We sent interested centres the full protocol and requested local institutional review board (IRB) approval.

Two questionnaires with multiple choice and openended questions were used. The unit data questionnaire focused on unit infrastructure, technology and provider ratios. The model of care questionnaire gathered data on providers, policies, limited clinical/ demographic data of currently admitted patients and the model of care employed in participating centres in relation to the IPPC curriculum: (1) holistic care, (2) family support, (3) child-family unit involvement, (4) pain and symptom control, (5) continuity of care and (6) grief and bereavement support (figure 1). ${ }^{10}$ All these were included in our questionnaires and each health provider that completed them did so while considering the admitted child and the questions related to the domains applied in the care of each child. Regarding supportive and palliative care as a continuum of care, it was explored in the domain of continuity of care. For each study site, 2 weeks were predefined to complete the questionnaires. Participants had a 100\% response survey completion rate.

\section{Data collection}

Data collection began after obtaining approval from each site's IRB. While we coordinated primarily with local principal investigators, any current PICU provider could complete the questionnaires.

In the model of care questionnaire, providers identified their ICU role and assessed how care was addressed in each patient's care; providers could explain further in optional open-ended questions. Participants did not disclose identifiable patient data; they reported patient 
age, sex, race, language(s), diagnosis and length of stay. Race and language were classified according to patient charts. We asked centres to complete 10-25 copies of the model of care questionnaire; if centres included additional patients, we did not exclude them. The patients included were all those children who fulfilled requirements to be admitted to the PICU and that were considered of having likelihood of benefit in their condition by being managed in the units (Association for Children's Palliative Care or ACT category 1). In other words, the patients needed management and monitoring that could not be provided outside the unit, but were not terminally ill, unless their disease trajectory led to a severe progression of illness and death. ${ }^{19}$ The mortality rates may vary within centres and depend on the type and complexity of cases that each PICU admits. Despite this, we did not report this parameter because it does not pertain to the objective of this study. Additionally, patients did not have a case manager. The participants in the care of these children include the paediatric critical care team including physicians, nurses and respiratory therapists, and in some units, psychologists, spiritual leaders, and other providers that are present through a consultation model.

We encouraged participants to complete the questionnaires on Research Electronic Data Capture (REDCap), ${ }^{20}$ an encrypted, password-protected online platform that permits primary users to create, share, analyse and store data entered into questionnaires. Respondents who could not use REDCap because of a lack of reliable internet sent de-identified responses via email.

\section{Statistical methods}

Structural and demographic characteristics obtained were summarised according to World Bank income group. ${ }^{18}$ Characteristics included number of beds, PICU area $\left(\mathrm{m}^{2}\right)$, available equipment (eg, ventilators, resuscitation), average unit census per day/week and PICU providers (eg, critical care physicians, nurses). We calculated the number of beds that each PICU provider covered by dividing number of beds by number of providers and number of equipment units by total number of beds. Continuous variables were categorised based on empirical analysis of our data and published literature. Descriptive statistics were reported using mean and SD for continuous variables and proportions for categorical variables.

To evaluate primary palliative care delivery, we constructed a partial score for each of the six domains evaluated in the model of care questionnaire. For each recommendation item within each domain, we assigned a numeric value to each answer: 'yes' $=1$, 'sometimes' $=0.5$ and 'no' $=0$. Some questions included the option of 'non-applicable' which was generally assigned a value of 0 with exceptions described here. Items referring to educational needs were only considered for children $\geq 4$ years (domain 1 -holistic needs) because formal schooling starts after this age. ${ }^{21}$ Thus, respondents may have considered that educational needs were not applicable to younger children. Questions regarding decision-making ability were considered for children $\geq 8$ years due to guidelines recommendations. ${ }^{22}$ During sensitivity analysis, we re-coded the 'non- applicable' option to 1 or missing and reassessed the analysis. To create a partial score within each domain, we summed scores for all items and converted them to a per cent such that the range of potential scores was $0-100$. Finally, a total index was created by averaging the per cent scores for each domain (potential final scores 0-100).

We compared each domain's average and total scores according to World Bank income group. To assess differences while accounting for potential bias, we used multilevel generalised linear models (GLMs) with a Gaussian distribution adjusted by child age and sex, using centres as a clustering variable. For statistical purposes, the high-income country (HIC) group was used as the reference group. We investigated the association between structural and demographic characteristics and total IPPC scores. For patient characteristics, we considered age, sex, race, length of stay and presence of comorbidities. For centre characteristics, number of ventilators and resuscitation equipment, per cent of daily bed use, beds per critical care physician/nurse and provider shift lengths. We evaluated associations using univariate and multivariable multilevel GLMs using centre as a clustering variable. Based on clinical and statistical considerations, the adjusted model included age, sex, race, comorbidities and shift length. We did not have any missing data. All statistical analysis was conducted using Stata V.14.1.

\section{Partial patient and public involvement}

Research participants (diverse healthcare professionals) aided in recruitment, data collection and drafting the final version of this manuscript. Following publication, the PICU-MIC research group and wider scientific community will have access to research data on request for their own analyses. Future PICU-MIC research group initiatives will include the co-development of plain language summaries and leaflets describing study results and ideas to improve primary PPC access in culturally relevant ways.

\section{RESULTS}

Our sample included 34 participating PICUs from 18 countries from North America (5), Latin America (7), Europe (5), Asia (15) and Africa (2). HIC units made up $32.4 \%$ of the sample, upper-middle income countries (UMICs) 44.1\% and lower-middle income/lower income countries (LMIC/LICs) 23.5\%. HICs generally had more doctors, nurses and respiratory therapists per unit, although the relationship between beds/ healthcare provider was less consistent compared with 
Table 1 Units' physical and human resources averaged by World Bank Country income group

\begin{tabular}{|c|c|c|c|c|c|c|c|c|c|c|c|c|c|c|c|c|}
\hline \multirow[b]{3}{*}{$\begin{array}{l}\text { World Bank } \\
\text { income group }\end{array}$} & \multicolumn{2}{|c|}{ General } & \multicolumn{4}{|c|}{ Equipment } & \multicolumn{4}{|c|}{ Average number of patients } & \multicolumn{6}{|c|}{ Healthcare providers } \\
\hline & \multirow{2}{*}{$\begin{array}{l}\text { Beds } \\
\text { n }\end{array}$} & \multirow{2}{*}{$\begin{array}{l}\text { Area } \\
\mathrm{m}^{2}\end{array}$} & \multicolumn{2}{|c|}{ Ventilators } & \multicolumn{2}{|c|}{ Resuscitation } & \multicolumn{2}{|c|}{ Per day } & \multicolumn{2}{|c|}{ Per week } & \multicolumn{2}{|c|}{$\begin{array}{l}\text { Critical care } \\
\text { doctors }\end{array}$} & \multicolumn{2}{|c|}{ Nurses } & \multicolumn{2}{|c|}{$\begin{array}{l}\text { Respiratory } \\
\text { therapists }\end{array}$} \\
\hline & & & $\mathrm{n}$ & $\begin{array}{l}\text { Per } \\
\text { bed }\end{array}$ & $\mathrm{n}$ & Per bed & $\mathrm{n}$ & $\begin{array}{l}\% \\
\text { beds } \\
\text { in use }\end{array}$ & $n$ & $\begin{array}{l}\text { Patients/ } \\
\text { bed per } \\
\text { week }\end{array}$ & $\mathrm{n}$ & $\begin{array}{l}\text { \# beds } \\
\text { per } \\
\text { doctor }\end{array}$ & $n$ & $\begin{array}{l}\text { \#beds } \\
\text { per } \\
\text { nurse }\end{array}$ & $\mathrm{n}$ & $\begin{array}{l}\text { \# beds per } \\
\text { therapist }\end{array}$ \\
\hline HIC & 19.5 & 965.0 & 14.2 & 1.00 & 4.1 & 0.30 & 15.2 & 73.4 & 68.7 & 2.0 & 12.5 & 3.0 & 14.0 & 1.6 & 2.5 & 5.0 \\
\hline UMIC & 10.9 & 329.0 & 12.1 & 1.09 & 5.0 & 0.47 & 10.8 & 90.0 & 23.2 & 1.9 & 7.9 & 2.6 & 4.6 & 2.6 & 1.2 & 3.4 \\
\hline LMIC+LIC & 9.1 & 166.0 & 6.9 & 0.81 & 4.9 & 0.69 & 7.3 & 80.2 & 20.3 & 1.9 & 7.4 & 1.6 & 4.6 & 2.2 & 0.6 & 2.6 \\
\hline
\end{tabular}

HIC, high-income countries; LIC+LMIC, lower income countries and lower-middle income countries; UMIC, upper-middle income countries.

units in lower income groups (table 1). HICs had the greatest number of patients, fastest patient turnover, lowest percentage of bed use, greater number of beds, and largest average unit area.

A total of 171 children $(34.3 \%)$ were in HICs, 227 (45.6\%) in UMICs and 100 (20.1\%) in LMIC/LICs. All income groups reported partial fulfilment of primary PPC resulting in an integrated model of care in the PICU. However, no group reported perfect fulfilment of any IPPC domain (figure 1).

After adjusting for patient age/sex and unit clustering, HICs had a higher total average score for all domains (63.0\%) than UMICs (44.6\%) or LMIC/LICs (47.2\%). This effect was only statistically significant for the comparison between HICs and UMICs ( $p$ value $=0.022$ )

Across all IPPC goals, HICs generally had higher scores than units in lower resource settings but not all comparisons were statistically significant (table 1 ). For domain 1 (holistic care of the child, all ages considered), HICs scored $72.7 \%(\mathrm{SD}=22.4)$ while UMICs scored $41.1 \%(S D=27.6) \quad(p$ value $=0.004$, adjusted for age, sex, clustering by unit).

In domain 2 (family support), HICs had a higher score than UMICs (p value=0.038). Similarly, HICs scored 23\% points higher than UMICs in domain 3B (family involvement) (adjusted $\mathrm{p}$ value $=0.006$ ).

HICs had higher scores in domain 6A (grief/bereavement support of the family) than LMIC/LICs ( $\mathrm{p}$ value: 0.025 ) and in domain $6 \mathrm{~B}$ (grief/bereavement support of healthcare providers) compared with LMIC/LICs ( $\mathrm{p}$ value: 0.001 ) and UMICs ( $p$ value $=0.002$ )

We also investigated associations between patient/ centre characteristics and IPPC scores. The IPPC domains were not applied differently according to diagnosis (table 2).

Table 3 shows total scores across all domains by patient and centre characteristics. Scores did not vary by patient sex/age. Patients with multiple comorbidities had, on average, slightly higher scores than patients with a single condition after adjusting for other covariates ( $\mathrm{p}$ value $=0.018$ ). There were no statistically significant associations between IPPC scores and equipment availability, per cent daily bed use or patient load/ healthcare provider. Shorter shift lengths ( $<8$ hours) had higher IPPC scores than centres with longer shift lengths, after adjusting for other covariates ( $\mathrm{p}$ value for trend: $<0.001$ ). During sensitivity analysis, we evaluated alternative coding of the 'non-applicable' option and did not find substantial differences on any of our results (not shown).

\section{DISCUSSION}

PPC is not at odds with intensive care; rather, it can improve ICU patients' quality and length of life..$^{1-357}$ We found universal though heterogeneous and overall insufficient fulfilment of IPPC recommendations; indicating that healthcare providers complete numerous palliative care tasks in PICUs worldwide, although inconsistently and imperfectly. In general, HICs units

\begin{tabular}{|c|c|c|}
\hline $\begin{array}{l}\text { Medical diagnosis } \\
\text { categories }\end{array}$ & Prevalence (\%) & $\begin{array}{l}\text { Total score, } \\
\text { mean (SD) }\end{array}$ \\
\hline Respiratory & 38.0 & $52.8(18.2)$ \\
\hline Nervous system & 28.9 & $53.4(17.0)$ \\
\hline Environmental* & 10.6 & $50.9(16.8)$ \\
\hline Infectious & 31.1 & $50.0(18.1)$ \\
\hline $\begin{array}{l}\text { Eye, ear, nose, throat, } \\
\text { craniofacial }\end{array}$ & 2.8 & $48.6(24.3)$ \\
\hline Neonatal & 13.4 & $57.6(17.5)$ \\
\hline Gastrointestinal/hepatobiliary & 15.7 & $50.0(17.9)$ \\
\hline Circulatory & 22.1 & $56.0(18.0)$ \\
\hline Othert & 0.4 & $58.3(35.7)$ \\
\hline Orthopaedic/musculoskeletal & 6.0 & $39.4(18.2)$ \\
\hline Endocrine/metabolical & 6.8 & $50.6(18.9)$ \\
\hline Haematological/oncological & 10.2 & $49.1(22.2)$ \\
\hline Renal/urological & 7.8 & $53.2(22.6)$ \\
\hline Ungroupable & 1.0 & $45.6(12.0)$ \\
\hline \multicolumn{3}{|l|}{ Medical/procedural } \\
\hline Procedural & 18.9 & $48.6(18.6)$ \\
\hline Abuse & 0.6 & $62.2(18.6)$ \\
\hline \multicolumn{3}{|l|}{ Number of comorbidities } \\
\hline $\begin{array}{l}\text { Single major diagnostic } \\
\text { category }\end{array}$ & 26.7 & $51.4(18.8)$ \\
\hline Multiple comorbidities & 73.3 & $51.5(18.5)$ \\
\hline Total & 100.0 & \\
\hline
\end{tabular}

*Including poisonings, burns and trauma.

tIncluding mental health disorders and alcohol and drug use. 
Table 3 Associations between patient and centre characteristics with the average total scores across the six Initiative for Paediatric Palliative Care domains

\begin{tabular}{|c|c|c|c|c|c|}
\hline & \multirow[b]{2}{*}{$\mathrm{N}$} & \multirow[b]{2}{*}{$\%$} & \multicolumn{3}{|c|}{ Total score all domains, \% } \\
\hline & & & Mean (SD) & P value* & Adjusted $p$ value* \\
\hline \multicolumn{6}{|l|}{ Patient characteristics } \\
\hline \multicolumn{6}{|l|}{ Age } \\
\hline Newborn (0-1 month) & 34 & 6.8 & $51.3(22.6)$ & 0.083 & 0.099 \\
\hline Infant (>1-12 months) & 122 & 24.5 & $53.0(17.7)$ & 0.388 & 0.459 \\
\hline Preschool (>1-5years) & 150 & 30.1 & $52.2(18.5)$ & Ref. & Ref. \\
\hline School (>5-11 years) & 103 & 20.7 & $47.4(19.6)$ & 0.942 & 0.650 \\
\hline Teen (>11-18years) & 89 & 17.9 & $52.9(16.7)$ & 0.259 & 0.228 \\
\hline \multicolumn{6}{|l|}{ Sex } \\
\hline Male & 285 & 57.2 & $50.4(19.1)$ & Ref. & Ref. \\
\hline Female & 213 & 42.8 & $52.8(17.8)$ & 0.878 & 0.744 \\
\hline \multicolumn{6}{|l|}{ Race } \\
\hline White & 173 & 35.8 & $56.5(20.7)$ & Ref. & Ref. \\
\hline Asian & 111 & 22.3 & $44.6(16.1)$ & 0.370 & 0.279 \\
\hline Black $†$ & 54 & 10.9 & $46.4(20.1)$ & 0.045 & 0.047 \\
\hline Indian & 31 & 6.2 & $55.5(4.8)$ & 0.436 & 0.448 \\
\hline Mestiza & 57 & 11.5 & $51.2(20.1)$ & 0.732 & 0.880 \\
\hline Middle-Eastern & 67 & 13.5 & $52.1(14.2)$ & 0.819 & 0.650 \\
\hline Other & 4 & 0.8 & $55.8(4.4)$ & 0.985 & 0.837 \\
\hline \multicolumn{6}{|l|}{ Days in paediatric intensive care unit } \\
\hline$<30$ days & 427 & 85.7 & $51.6(18.9)$ & Ref. & \\
\hline$\geq 30$ days & 71 & 14.3 & $50.5(16.3)$ & 0.431 & \\
\hline \multicolumn{6}{|l|}{ Comorbidities } \\
\hline Single Major Diagnostic Category & 133 & 26.7 & $51.4(18.8)$ & Ref. & Ref. \\
\hline Multiple comorbidities & 365 & 73.2 & $51.5(18.5)$ & 0.017 & 0.018 \\
\hline \multicolumn{6}{|l|}{ Centre characteristics } \\
\hline \multicolumn{6}{|l|}{ Number of ventilators } \\
\hline$<1$ per bed & 238 & 47.8 & $49.6(15.1)$ & Ref. & \\
\hline$\geq 1$ per bed & 260 & 52.2 & $53.1(21.2)$ & 0.811 & \\
\hline \multicolumn{6}{|l|}{ Resuscitation equipment } \\
\hline$<0.5$ per bed & 360 & 72.3 & $50.3(20.0)$ & Ref. & \\
\hline$\geq 0.5$ per bed & 138 & 27.7 & $54.3(13.8)$ & 0.509 & \\
\hline \multicolumn{6}{|l|}{ Per cent daily bed use } \\
\hline$<80 \%$ & 176 & 35.3 & $52.4(22.2)$ & Ref. & \\
\hline$\geq 80 \%$ & 322 & 64.7 & $50.9(16.3)$ & 0.792 & \\
\hline \multicolumn{6}{|l|}{ Beds per critical care doctor } \\
\hline$<2$ beds per doctor & 319 & 68.5 & $50.5(19.3)$ & Ref. & \\
\hline$\geq 2$ beds per doctor & 147 & 31.6 & $51.6(17.9)$ & 0.884 & \\
\hline \multicolumn{6}{|l|}{ Beds per nurse } \\
\hline$<2$ beds per nurse & 245 & 54.8 & $54.0(19.8)$ & Ref. & \\
\hline$\geq 2$ beds per nurse & 202 & 45.2 & $47.6(17.6)$ & 0.212 & \\
\hline \multicolumn{6}{|l|}{ Shift length } \\
\hline$<8$ hours & 102 & 20.5 & $67.1(13.7)$ & Ref. & Ref. \\
\hline $8-12$ hours & 241 & 48.4 & $53.4(15.1)$ & 0.079 & 0.056 \\
\hline 13-18hours & 42 & 8.4 & $47.1(22.5)$ & 0.056 & 0.052 \\
\hline 19-24hours & 20 & 4.0 & $35.6(24.1)$ & 0.010 & 0.006 \\
\hline Multiple & 93 & 18.7 & $34.4(8.76)$ & 0.001 & $<0.001$ \\
\hline$P$ value for trend & & & & $<0.001$ & $<0.001$ \\
\hline
\end{tabular}

Bold values are those found to be statistically significant ( $p$-value $<0.05)$.

* $P$ values were estimated using univariate and multivariable multilevel generalised linear models using centre as a clustering variable. The adjusted model included age, sex, race, comorbidities and shift length.

†After subanalysis of this variable, considering many children in the universe were of black ethnicities, we do not consider this finding significative. 
exhibited better adherence to the delivery of primary palliative care than units in lower income groups. In addition, units with shorter shift lengths had higher overall IPPC scores than units with longer shift lengths. Although the integrated model of care was applied in diverse settings, all units surveyed had opportunities for considerable improvement. Building on these existing competencies in specific tasks may help disseminate the integrated model of care combining critical care and primary palliative care and ultimately improve the quality of care and life. Furthermore, few units might have a dedicated palliative care team for the PICU due to a deficiency of trained professionals or because of an expected positive prognosis of most children that are admitted to the PICUs. ${ }^{1}$ Despite this, children whose lives are at risk can benefit from a primary PPC approach that can be combined with critical care.

In agreement with other evidence, we found that primary PPC was generally better developed in HICs. ${ }^{2}$ There was also a statistically significant difference in overall IPPC scores between HICs and UMICs. However, broad statements about the inadequacy of PPC in under-resourced settings are limited in their utility to redress well-documented disparities. For example, it was unsurprising that HICs had more beds and paediatric critical care doctors and nurses available/bed. However, despite these variations in technology, resources and bed use patterns, we did not find any evidence showing that they were directly related to fulfilment of IPPC curriculum. Only shorter shift lengths were associated with higher IPPC' curriculum application.

Additionally, ICU use, charity, sector-driven differences and sociopolitical factors mediate medical equipment access and distribution. ${ }^{23-25}$ Similarly, legally-mandated, ideal and actual ICU personnelto-patient ratios vary widely 2425 and are dependent on healthcare provider supply, ${ }^{24}$ education infrastructure ${ }^{24}$ healthcare provider mobility ${ }^{26}$ and other factors. ${ }^{24} 25$ 27-29 While human and physical resource availability undoubtedly shape quality of care,${ }^{15}$ variations within our sample were not associated with IPPC's curriculum fulfilment. This suggests that foundations necessary to implement these interventions already exist, regardless of income. ${ }^{30}$ These findings harken back to the WHO's definition of PPC, which states that PPC can be delivered using available community resources, even in low-income settings. ${ }^{2} 31$

Overall, domains concerned with family support (domain 2), symptom relief ${ }^{4}$ and continuity of care ${ }^{5}$ were best fulfilled, although there were opportunities for improvement. Linking interventions to address lessdeveloped aspects of care (eg, bereavement support) with domains with better delivery (eg, continuity of care) may facilitate improvements. In our study, HICs had higher IPPC scores compared with UMICs in four domains (domain 1 holistic care; domain 2 family support; domain 3B family involvement; domain 6B grief/bereavement healthcare provider support) and higher IPPC scores compared with LMIC/LICs in two domains (domain 6A grief/bereavement family support; domain $6 \mathrm{~B}$ grief/bereavement healthcare provider support).

Holistic, family-centred care may be overall better developed in HICs because it requires the integration of diverse specialties and sectors, whole-person care, patient/family-focused care and quality of care evaluation. ${ }^{32}$ In under-resourced settings, limited infrastructure $^{3233}$ and medical education ${ }^{33}$ may constrain such pillars. However, LMICs/LICs have been lauded for better coordination, communication, collaboration, innovation and extra-specialty competence in the absence of formal structures and systemic support. ${ }^{32}$ It is beyond our study's scope to determine why UMICs had statistically significant lower scores than LMIC/ LICs in domains 1 holistic care of the child and 3B family involvement, and statistically non-significantly lower scores in other domains. We speculate that UMICs' economic transition may result in barriers characteristic of wealthier economies (eg, extreme specialty exclusivity, reliance on technology/formal structures $^{32}$ ) when compared with LMIC/LICs (eg, limited infrastructure ${ }^{2}{ }^{32}$ ) that might limit quality of care. Additionally, lower-resource centres scores may have been affected by a lack of external ethics consultation and standardised national guidelines, which are not universally available.

Although the importance of bereavement support is widely-documented, ${ }^{34-37}$ centres complied with only $36.8 \%$ of IPPC's curriculum for family bereavement support and $38.3 \%$ of recommendations for healthcare providers. Few studies have investigated service prevalence, particularly in PICUs and low-resource settings. ${ }^{38}$ Evidence suggests that most adult ICUs in HICs do not offer bereavement services; those that do are limited (eg, offering brochures). ${ }^{38}$

Service provision barriers include staff discomfort and lack of financial resources, time and training. ${ }^{38}$ Furthermore, palliative care service development and perceptions of child/neonatal death may influence bereavement support. ${ }^{34}$ The losses that ICU staff face can be burdensome and may affect long-term functioning. ${ }^{39}$ However, recognising staff's grief support needs may be discouraged in ICU culture. ${ }^{39}$ Although beneficial, ${ }^{39}$ services may be insufficient because of limited resources, the routinisation of child death and the higher PICU mortality rates in many underresourced settings. ${ }^{7}$

In domain 3A (child involvement), scores were universally low. Varying protections and culture influence children's participation in medical decisionmaking. ${ }^{72130}$ Furthermore, limited use of standardised assessment tools may lead to inconsistent evaluation of children's decision-making abilities.

Our study had several strengths. We investigated diverse possible determinants of primary PC provision, 
including unit characteristics (eg, physical space, number of beds, medical technology) human resources (eg, staff ratios, shift lengths), patient characteristics (eg, race, language, sex, comorbidities) and country income. Additionally, our sample was diverse and included constituents often excluded from medical research due to geographical, linguistic, or resource limitations. We also considered diverse PPC indicators based on an evidence-based curriculum ${ }^{10}$ to provide a complete picture of the primary palliative care provision in participating units. Contrastingly, our study also had several limitations. Centres are not generalisable country representatives. Additionally, we did not ask centres to identify whether they were from urban, suburban or rural localities or if they were located within public, private or public-private institutions; these variables should be considered in the future. It was beyond our study's scope to determine the causes of the statistically significant IPPC score differences. Participating units' mortality rates, disability prior to discharge, and consistency of PPC application over time were not studied.

From a capacity development perspective, studying how, where, why and by whom interventions are applied can help maximise the implementation of innovations like the IPPC curriculum. ${ }^{12-14}$ Research must continue to investigate pertinent characteristics of potential adopters and clinical environments to maximise application and improve primary palliative care access. Finally, it is crucial to consider barriers to the practice of evidence-based healthcare. The mere dissemination of tools like the IPPC curriculum is not independently sufficient to spur widespread implementation. ${ }^{11}$

\section{CONCLUSION}

Creating evidence-based recommendations is just one link in a chain of interventions necessary to disseminate primary PPC clinical knowledge and practices, and apply an integrated model of care. Studies like this are an important step in translating evidence-based recommendations to practice. Furthermore, understanding the current application of the IPPC curriculum can help identify opportunities to apply other elements of implementation effectiveness research to improve intervention adoption. Many chronically and critically ill children are admitted every day to PICUs worldwide, and critical care healthcare providers should have the skills to provide primary palliative care when needed. Our research contributed to the concept of an integrated model of care at the PICU, in which critical care and primary palliative care could be delivered by the team of paediatric critical care health providers, depending on the trajectory of illness. An emphasis should be made in including these skills during residency training. In turn, maximising dissemination of the integrated model of care, ultimately facilitating children's human right to PPC access.
Acknowledgements We thank the PICU-MIC investigators $†$ for their collaboration, Dr Andrea Cordero for initial project coordination and the Universidad San Francisco de Quito's Collaboration Grant, which funded this research.

Collaborators +PICU-MIC investigators: (1) Jorge López González, MD; Jesús López-Herce, MD-Hospital General Universitario Gregorio Marañón-UCIP; Facultad de Medicina Universidad Complutense de Madrid, Madrid, Spain. (2) Emanuele Rossetti, MD; Chiusolo Fabrizio, MD-Ospedale Pediatrico Bambino Gesù-PICU, Roma, Italy. (3) Oliver Karam, MD, PhD, Marie Saint-Faust, MD_Geneva University Hospitals-HUG PICU, Geneva, Switzerland. (4) Paolo Biban, MD; Silvia Carlassara, MD-Azienda Ospedaliera Universitaria Integrata Verona PICU, Verona, Italy. (5) Bettina von Dessauer, MD; Nadia Ordenes, MD—Hospital de Niños Roberto del Río-Unidad de Paciente Crítico Pediátrico, Santiago, Chile. (6) Fabiola Figueroa Urízar, MD; Adriana Wegner A, MDHospital Sótero Del Río-UCIP, Santiago, Chile. (7) Michael Canarie, MD-Yale-New Haven Children's Hospital's Pediatric Intensive Care Unit, New Haven, Connecticut, USA. (8) Kathryn Miller, MD-University Hospitals Cleveland Medical Center-PICU, Cleveland, Ohio, USA. (9) José Irazuzta, MD; Nicolas Chiriboga, MD-University of Florida COM-PICU, Jacksonville, Florida, USA. (10) Daniel Tawfik, MD, MS; Barbara Sourkes, PhD; Nancy Ewen Wang, MD; Hursuong Vongsachang-Division of Pediatric Critical Care Medicine at Stanford University Medical Center-PICU, Stanford, CA, USA. (11) Elizabeth W. Tucker, MD; Nicole Shilkofski, MD, MEd; The Johns Hopkins Children's Center PICU, Baltimore, MD, USA. (12) 王文超 Wang Wenchao, RN; Zhang Yuxia, RN, PhD; Pediatric Hospital of Fudan University-PICU-Fudan, China. (13) Lucy Lum Chai See, MD; Sister Priscilla-University Malaya Medical Center-PICU, Kuala Lumpur, Malaysia. (14) Recep Tekin, MD; Fesih Aktar, MD-Dicel University Medical Hospital-PICU; Diyarbakir, Turkey. (15) Duygu Sönmez Düzkaya, CPN, PhD-Istanbul University Faculty of Medicine PICU; Istanbul, Turkey. (16) Oguz Dursun, MD; Ebru Atike Ongun, MD-Akdeniz University-Faculty of Medicine PICU; Antalya, Turkey. (17) Resul Yilmaz, MD-Gaziosmanpasa University School of Medicine Tokat- PICU-Tokat, Turkey. (18) Dincer Yildizdas, MD-Çukurova University, Faculty of Medicine; Balcali Hospital, PICU-Adana, Turkey. (19) Hakan Tekgüç, MD—Koru Hospital-PICU; Ankara, Turkey. (20) Vitaliy Sazonov, MD; Timur Tsoy, MD—PICU of City Children Hospital; Astana, Kazakhstan. (21) Vitaliy Sazonov, MD; Askhat Saparov, MD-PICU of National Research Center for Maternal and Child Health; Astana, Kazakhstan. (22) Vitaliy Sazonov, MD; Elizaveta Kalmbakh, MD-PICU of Karaganda Regional Children's Hospital, Karaganda, Kazakhstan. (23) Michelle Grunauer, MD, PhD (USFQ/ HDLV); Ernesto Quiñones, MD (HDLV); Luis Eguiguren, MD (USFQ); Andrea P. Icaza-Freire, MD (USFQ); Killen Briones, MD (UG, CFRBC, ICU, ICU IESS); UCIP/UCIN del Hospital de los Valles, Quito, Ecuador; Universidad San Francisco de Quito, Facultad de Medicina, Quito, Ecuador; Universidad de Guayaquil, Facultad de Ciencias Médicas, Guayaquil, Ecuador; Centro Fisiológico-Respiratorio Briones-Claudett, Guayaquil; ICU Panamerican Clinic, Guayaquil; ICU IESS de Babahoyo, Ecuador. (24) Antonio WD Gavilanes, MD-Department of Pediatrics, University Medical Center Maastricht, Maastricht, The Netherlands. (25) Yaneth Tovilla, MD-Unidad Pediátrica de Quemados de los Servicios de Salud del Estado de Puebla, Puebla, México. (26) Sandra Tania Ventura Gómez, MD-UCIP del Hospital Regional de Alta Especialidad de Ixtapaluca, Ixtapaluca, México. (27) Silvio Fabio Torres, MD, MSc_-Pediatric Intensive Care Unit, Hospital Universitario Austral; Buenos Aires, Argentina. (28) Paul Cobarrubias, MDAmang Rodriguez Memorial Medical Center-PICU, Manila, Philippines. (29) Dmytro Dmytriiev, MD—Vinnitsa National Medical University-PICU, Vinnitsa, Ukraine. (30) Alejandro Martínez, MD; Gustavo Guzaman, MD; Rudy Sanabria, MDHospital del Niño Manuel Ascencio Villarroel, Cochabamba- 
UTIP, Cochabamba, Bolivia. (31) Ravikumar Krupanandan, MD; Bala Ramachandran, MD-PICU, Kanchi Kamakoti CHILDS Trust Hospital, Chennai, India. (32) Nirmal Choraria, MD; Jignesh Patel, MD; PICU-Nirmal Hospital, Ltd.; Surat, India. (33) Puneet A Pooni, MD; Karambir Singh Gill, MDDayanand Medical College Punjab, India. (34) John Adabie Appiah, MD; Komfo Anokye Teaching Hospital-PICU, Kumasi, Ghana. (35) Tigist Bacha Heye, MD; Rahel Argaw, MD; Asrat Demtse, MD; Israel Abebe Admasu, MD_Addis Ababa University, College of Health Sciences-PICU, Addis Ababa, Ethiopia.

Contributors The corresponding author Dr Michelle Grunauer 'had full access to all the data in the study and takes responsibility for the integrity of the data and the accuracy of the data analysis'. Gabriela Bustamante, MPH, $\mathrm{PhD}$, conducted and is responsible for the data analysis. Only MG, CM and GBC had access to the full data set prior to publication. $\mathrm{MG}, \mathrm{CM}$ and $\mathrm{GBC}$ contributed to the following in the elaboration of this investigation: Substantial contributions to the conception or design of the work and the acquisition, analysis or interpretation of data for the work, critical revision for important intellectual content, final approval of the version to be published, agreement to be accountable for all aspects of the work in ensuring that questions related to the accuracy or integrity of any part of the work are appropriately investigated and resolved. PICU-MIC Research Group investigators contributed to the following in the elaboration of this investigation: Substantial contributions to the conception or design of the work and the data acquisition.

Funding This study was supported by the Universidad San Francisco de Quito's Collaboration Grant 2016-091IN to MG. The Universidad San Francisco de Quito-Collaboration Grants Committee, the funder of this research, played no role in 'design and conduct of the study; collection, management, analysis, and interpretation of the data; preparation, review or approval of the manuscript; and decision to submit the manuscript for publication'.

\section{Competing interests None declared.}

Patient consent for publication Not applicable.

Ethics approval The Universidad San Francisco de Quito's Ethics Committee for Research of Human Beings/Institutional Review Board approved this research (2016-091IN). Also approved by the ethics committees of all sites of the PICU-MIC Research Group prior to data collection beginning.

Provenance and peer review Not commissioned; externally peer reviewed.

Data availability statement Data are available upon reasonable request.

Open access This is an open access article distributed in accordance with the Creative Commons Attribution Non Commercial (CC BY-NC 4.0) license, which permits others to distribute, remix, adapt, build upon this work noncommercially, and license their derivative works on different terms, provided the original work is properly cited, appropriate credit is given, any changes made indicated, and the use is noncommercial. See: http://creativecommons.org/licenses/by-nc/4. $0 /$.

\section{ORCID iDs}

Michelle Grunauer http://orcid.org/0000-0002-5821-7603

Caley Mikesell http://orcid.org/0000-0001-5380-7930

Gabriela Bustamante Callejas http://orcid.org/0000-0002-22277209

\section{REFERENCES}

1 Grunauer M, Mikesell C. A review of the integrated model of care: an opportunity to respond to extensive palliative care needs in pediatric intensive care units in Under-Resourced settings. Front Pediatr 2018;6:3.
2 World Palliative Care Alliance, World Health Organization. Global atlas of palliative care at the end of life, 2014. Available: https://www.who.int/nmh/Global_Atlas_of Palliative_Care.pdf [Accessed 20 Oct 2019].

3 World Health Organization. WHO definition of palliative care. Available: http://www.who.int/cancer/palliative/definition/en/ [Accessed 20 Oct 2019].

4 Boss R, Nelson J, Weissman D, et al. Integrating palliative care into the PICU: a report from the improving palliative care in the ICU Advisory board. Pediatr Crit Care Med 2014;15:762-7.

5 Nelson JE, Bassett R, Boss RD, et al. Models for structuring a clinical initiative to enhance palliative care in the intensive care unit: a report from the IPAL-ICU project (improving palliative care in the ICU). Crit Care Med 2010;38:1765-72.

6 Casarett D, Johnson M, Smith D, et al. The optimal delivery of palliative care: a national comparison of the outcomes of consultation teams vs inpatient units. Arch Intern Med 2011;171:649-55.

7 Chambers L, Goldman A. A Guide to Children's Palliative Care: Supporting babies, children and young people with life-limiting and life-threatening conditions and their families. Fourth Edition. Bristol, England: Together for Short Lives, 2018. https://www.togetherforshortlives.org.uk/wp-content/ uploads/2018/03/TfSL-A- Guide-to-Children\%E2\%80\%99sPalliative-Care-Fourth-Edition-5.pdf

8 Gans D, Kominski GF, Roby DH, et al. Better outcomes, lower costs: palliative care program reduces stress, costs of care for children with life-threatening conditions. Policy Brief UCLA Cent Health Policy Res 2012:1-8.

9 Curtis K, Foster K, Mitchell R, et al. Models of care delivery for families of critically ill children: an integrative review of international literature. J Pediatr Nurs 2016;31:330-41.

10 Dokken DL, Heller KS, Rushton $\mathrm{CH}$. The initiative for pediatric palliative care. quality domains, goals, and indicators of family-centered care of children living with life-threatening conditions. Education Development Center 2001:1-10.

11 Rycroft-Malone J, Harvey G, Seers K, et al. An exploration of the factors that influence the implementation of evidence into practice. J Clin Nurs 2004;13:913-24.

12 Greenhalgh T, Robert G, Macfarlane F, et al. Diffusion of innovations in service organizations: systematic review and recommendations. Milbank Q 2004;82:581-629.

13 Helfrich CD, Weiner BJ, McKinney MM, et al. Determinants of implementation effectiveness: adapting a framework for complex innovations. Med Care Res Rev 2007;64:279-303.

14 Conn JJ, Lake FR, McColl GJ, et al. Clinical teaching and learning: from theory and research to application. Med J Aust 2012;196:527.

15 Campos-Miño S, Sasbón JS, von Dessauer B. [Pediatric intensive care in Latin America]. Med Intensiva 2012;36:3-10.

16 Penoyer DA. Nurse staffing and patient outcomes in critical care: a Concise review. Crit Care Med 2010;38:1521-8.

17 Bastos PG, Knaus WA, Zimmerman JE, et al. The importance of technology for achieving superior outcomes from intensive care. Brazil APACHE III study Group. Intensive Care Med 1996;22:664-9.

18 The World Bank. World bank country and lending groups. the world bank. Available: https://datahelpdesk.worldbank. org/knowledgebase/articles/906519-world-bank- country-andlending-groups [Accessed October 20, 2019].

19 Chang DW, Dacosta D, Shapiro MF. Priority levels in medical intensive care at an academic public hospital. JAMA Intern Med 2017; 177:280-1.

20 Harris PA, Taylor R, Thielke R, et al. Research electronic data capture (REDCap)-a metadata-driven methodology and workflow process for providing translational research informatics support. J Biomed Inform 2009;42:377-81. 
21 The World Bank. The world bank. primary school starting age (years), 2019. Available: https://data.worldbank.org/indicator/ SE.PRM.AGES [Accessed 20 Oct 2019].

22 Katz AL, Webb SA. Committee on bioethics. treatment decisions regarding infants, children and adolescents. Paediatr Child Health 2004;9:99-114.

23 Vian T. Review of corruption in the health sector: theory, methods and interventions. Health Policy Plan 2008;23:83-94.

24 Prin M, Wunsch $\mathrm{H}$. International comparisons of intensive care: informing outcomes and improving standards. Curr Opin Crit Care 2012;18:700-6.

25 Slusher TM, Kiragu AW, Day LT, et al. Pediatric critical care in resource-limited Settings-Overview and lessons learned. Front Pediatr 2018;6:49.

26 Aluttis C, Bishaw T, Frank MW. The workforce for health in a globalized context--global shortages and international migration. Glob Health Action 2014;7:23611.

27 Rosa W. Assessing the readiness of nursing sectors in low- and middle-income countries to adopt holistic practice: Rwanda as exemplar. Holist Nurs Pract 2017;31:183-92.

28 Short SR, Thienprayoon R. Pediatric palliative care in the intensive care unit and questions of quality: a review of the determinants and mechanisms of high-quality palliative care in the pediatric intensive care unit (PICU). Transl Pediatr 2018;7:326-43.

29 Baird J, Rehm RS, Hinds PS, et al. Do you know my child? continuity of nursing care in the pediatric intensive care unit. Nurs Res 2016;65:142-50.
30 Tripathi S, Kaur H, Kashyap R, et al. A survey on the resources and practices in pediatric critical care of resource-rich and resource-limited countries. J Intensive Care 2015;3:40.

31 Amery J. A Really Practical Handbook of Children's Palliative care for doctors and nurses Anywhere in the World. Morrisville: Lulu Publishing Services, 2016: 446p.

32 Mounier-Jack S, Mayhew SH, Mays N. Integrated care: learning between high-income, and low- and middle-income country health systems. Health Policy Plan 2017;32:iv6-12.

33 Baker T. Critical care in low-income countries. Trop Med Int Health 2009; 14:143-8.

34 Snaman JM, Kaye EC, Torres C, et al. Helping parents live with the hole in their heart: the role of health care providers and institutions in the bereaved parents' grief journeys. Cancer 2016;122:2757-65.

35 Butler AE, Hall H, Willetts G, et al. Family experience and PICU death: a Meta-Synthesis. Pediatrics 2015;136:e961-73.

36 Bauchner H, Fontanarosa PB, Death FPB. Death, dying, and end of life. JAMA 2016;315:270-1.

37 Doorenbos A, Lindhorst T, Starks H, et al. Palliative care in the pediatric ICU: challenges and opportunities for family-centered practice. J Soc Work End Life Palliat Care 2012;8:297-315.

38 McAdam JL, Erikson A. Bereavement services offered in adult intensive care units in the United States. Am J Crit Care 2016;25:110-7.

39 Crowe S, Sullivant S, Miller-Smith L, et al. Grief and burnout in the PICU. Pediatrics 2017;139. doi:10.1542/peds.20164041. [Epub ahead of print: 1804 2017]. 